\title{
Gastrointestinal symptoms - an illness burden that affects daily work in patients with IBS
}

\author{
Åshild Faresjö ${ }^{1 *} \mathbb{D}$, Susanna Walter ${ }^{2}$, Anna-Karin Norlin ${ }^{1}$, Tomas Faresjö ${ }^{1}$ and Michael P. Jones ${ }^{3}$
}

\begin{abstract}
Background: Irritable Bowel Syndrome (IBS) is a chronic gastrointestinal disorder characterised by recurrent abdominal pain and disturbed bowel habits and unclear aetiology. IBS is also associated with psychosocial factors, impaired quality of life and lost work productivity. This study sought to determine whether the association between IBS and lost work productivity might be accounted for by poor coping strategies and loss of confidence in the healthcare system.

Methods: Case-control design was employed sampling IBS and non-gastrointestinal (non-GI) primary healthcare seekers in a defined region in Sweden. Non-Gl patients were of similar age and sex distribution to the IBS patients. Questionnaires applied in this study included instruments designed to measure confidence in the social security system and in the community, as well as questions about whether gastrointestinal problems might affect working life and Sense of coherence (SOC) questionnaire. The study's primary hypothesis was evaluated via an a priori path model.
\end{abstract}

Results: Statistically significant differences were found between IBS cases $(n=305)$ and controls $(n=369)$ concerning abdominal pain or discomfort affecting everyday performance at work ( $p<0.0001)$. IBS cases also showed significantly lower $(p=0.001)$ confidence in public healthcare. The study's hypothesis was supported with the finding of a statistically significant indirect association via poor coping strategies, although the indirect associations were lesser in magnitude than the direct association.

Conclusions: This study found a clear association between clinically diagnosed IBS status and interference in work by gastrointestinal symptoms in which sense of coherence might be of importance.

Keywords: IBS, Disease burden, Sense of coherence, Confidence in public health

\section{Introduction}

Irritable Bowel Syndrome (IBS) is a chronic, relapsing gastrointestinal disorder characterised by recurrent abdominal pain and disturbed bowel habits [1, 2]. The diagnosis is based on symptoms and exclusion of organic gastrointestinal disease and affects $10-15 \%$ of the general population and has a female predominance [3-5]. IBS is subtyped according to the predominant symptoms into constipation (IBS-C), diarrhoea (IBS-D) mixed (IBS-M) and unspecified (IBS-U) [6].

\footnotetext{
* Correspondence: ashild.olsen.faresjo@liu.se

${ }^{1}$ Department of Medicine and Health, Community Medicine, Faculty of Medicine and Health Sciences, Linköping University, SE-581 83 Linköping, Sweden

Full list of author information is available at the end of the article
}

The aetiology of IBS remains unclear but disturbance of function along the brain-gut axis has been proposed $[7,8]$. To date, no specific biological abnormality has been identified that could explain the symptoms with specific exceptions such as post-infectious IBS [9]. However, well known theories about the pathophysiology of IBS include gastrointestinal dysmotility, visceral hypersensitivity, low-grade inflammation, increased intestinal mucosal permeability, immunological and genetic factors as well as altered intestinal microbiota [9-13]. IBS is also associated with psychosocial factors such as impaired quality of life, comorbid psychiatric disorders, chronic life stress and impaired coping. The heterogeneity of pathophysiological and psychosocial

(c) The Author(s). 2019 Open Access This article is distributed under the terms of the Creative Commons Attribution 4.0 International License (http://creativecommons.org/licenses/by/4.0/), which permits unrestricted use, distribution, and reproduction in any medium, provided you give appropriate credit to the original author(s) and the source, provide a link to the Creative Commons license, and indicate if changes were made. The Creative Commons Public Domain Dedication waiver (http://creativecommons.org/publicdomain/zero/1.0/) applies to the data made available in this article, unless otherwise stated. 
factors has led to the concept of a bio-psychosocial disease model in IBS [14-20]. IBS affects adults of all ages and especially those of working ages [21], often resulting in gastrointestinal problems that affect daily performance and productivity in working life, and lead to a greater extent of short periods of sick leave and impaired health-related quality of life (HRQL) [16, 22, 23]. Dibonaventura et al. showed that reduced productivity while at work in IBS-C patients was important as a contributor to total reduced work productivity, and that IBS-C patients experienced even more reduction in work productivity than a comparison group without IBS [24]. Faecal incontinence (FI) may also play a role in work impairment a recent study showed more impairment in IBS patients with comorbid FI [25].

Individuals use different coping strategies to manage illness and stress, which is also relevant for those affected by IBS $[26,27]$. These coping strategies can have positive effects, but might also have negative effects on their health status. Coping strategies using avoidant behaviour are characterised by a tendency to escape rather than to manage difficulties. This behaviour is related to an increase in self-blame and could lead to poor psychological adjustment i.e. lower coping ability [26]. A recent study using Sense of coherence (SOC) showed inferior coping strategies in IBS patients compared to non-IBS patients [17]. Drossman and co-workers demonstrated in patients with IBS that illness behaviour was the strongest predictor of the severity of functional bowel disorders [27].

To our knowledge, few studies have been conducted that examine the association between SOC and work productivity in IBS patients. We therefore conducted this study with the aim of investigating the role of Sense of coherence in work productivity among patients diagnosed with IBS compared with patients without any present gastrointestinal complaints in a primary care setting. We hypothesised that individuals with IBS might have inferior coping strategies and less confidence in the public health system, which might both directly and indirectly reduce their productivity in working life.

\section{Material and methods}

\section{Study population and design}

The study adopted a case-control design focussing on patients diagnosed with IBS, i.e. IBS cases in a defined region in south-east Sweden (The County Council of Östergötland). Ten Primary Healthcare centres (PHCs), in the three major cities of the region joined the study. These PHCs are responsible for primary care of a population of around 150,000 inhabitants $(1 / 3$ of the entire population of the county) [28]. The selected ten PHCs were chosen based on defined criteria to ensure diversity concerning socioeconomic status, age of population and number of immigrants. Subjects within the normal working age (range 18-65 years) with a known IBS diagnosis, diagnosed by a physician and active symptoms during the last two years identified in the patient medical register of the selected PHC were invited to participate in the study. The control group comprised other patients at these healthcare centres with a similar age and sex distribution, who sought care for other but less serious complaints not associated with GI symptoms and with no GI diagnoses found in the patient register for the previous two years. Patients who agreed to participate after an invitation letter completed questionnaires and returned them by mail in pre-paid envelopes. A total of 1135 invitations were mailed out, of which $n=754$ individuals agreed to participate, yielding an initial response rate of $66 \%$. However, $n=188$ individuals who agreed to participate did not return a questionnaire, yielding a final response rate of $50 \%$. A total of $n=305$ IBS patients agreed to participate in this study, and patients without IBS and any present or previous GI complaints comprised $n=369$ controls.

\section{Questionnaire}

Questionnaires applied in this study include instruments designed to measure confidence in the social security system and in the community and derives from The Swedish Living Conditions Survey of Health and Welfare Survey [29]. Further, questions were asked about whether gastrointestinal problems might affect working life as well as the Sense of coherence questionnaire and questions to define IBS according to the ROME III criteria [30].

\section{Sense of coherence (SOC)}

Sense of coherence is a theoretical construct explaining differences in how people perceive the world around them and thereby how they tend to cope with stressful and strenuous situations. This concept includes three main components: comprehensibility (the ability to understand what happens), manageability (to what extent the person was able to manage the situation) and meaningfulness (the ability to find meaning in the situation) [31]. This concept has been suggested as explaining how individuals cope with stressors in their lives. The higher the score, the more effective their coping strategy and the better their health outcome. The Swedish version of Antonovsky's 13-item questionnaire (SOC-13) was used in this study [32]. Every item is scored on a Likert scale ranging from 1 to 7 points. Thus, the total score ranges from 13 to 91 points. This 13-item version of SOC has been shown to be reliable, valid and cross-culturally applicable when evaluating how well people can manage stress and still be healthy [33]. 
Education was divided into three categories: low (primary school), medium (secondary or upper secondary school), or high (college or university). Marital status was dichotomised into the categories: 1) living alone or 2) married or living together. Occupational status was divided into five categories: employed, unemployed, retired, on sick-leave or student. Questions about whether gastrointestinal problems affect daily performance in working life offered four possible responses: yes absolutely, yes partly, no it does not affect my daily work, no I have no gastrointestinal problems. Questions about confidence in the healthcare system offered five possible responses: great confidence, quite a lot of confidence, not very much confidence, no confidence, and have no idea.

\section{Statistical analyses}

The design of the analysis in this study can be summarised according to the model shown in Fig. 1. To examine whether the association between IBS status and interference with work by gastrointestinal symptoms might operate indirectly via either Sense of coherence or confidence in the healthcare system or not, an a priori path model was fitted, as described in Fig. 1. If the indirect paths in the model account for a substantial fraction of the association, there is a possibility that Sense of coherence or confidence in the healthcare system are important in explaining the association between IBS and interference. Since the model is being estimated from a cross-sectional design it is important to note that causal interpretations cannot be made from it but the findings are an important first step that should be followed up using a longitudinal design. Due to violation of the assumption of multivariate Normality, formal statistical inference (calculation of standard errors and hypothesis testing) has been undertaken using the nonparametric bootstrap. All path coefficients (measures of association) are report in standardised form to facilitate comparability. Model fit is not directly relevant to the research question, so it is not reported. The key metric is the fraction of the total association between IBS and interference with work is indirectly via Sense of coherence and confidence in the health system. Quantitative variables are described using mean and standard deviation (s.d.) while qualitative (categorical) variables are described using counts and percentages. Comparisons between IBS cases and controls were undertaken using Pearson Chi-Square tests for quantitative variables and qualitative variables.

\section{Results}

For the total sample ( $N=668$ IBS cases and controls) there was a predominance of females for both groups and the mean age was significantly higher $(p<0.0001)$ for IBS cases 46.7 (s.d. 13.0) compared to 51.4 years (s.d. 11.8) for controls. Regarding psychosocial environment, the IBS cases significantly $(p<0.0001)$ tended to live alone more, and had a lower education level $(p=0.002)$

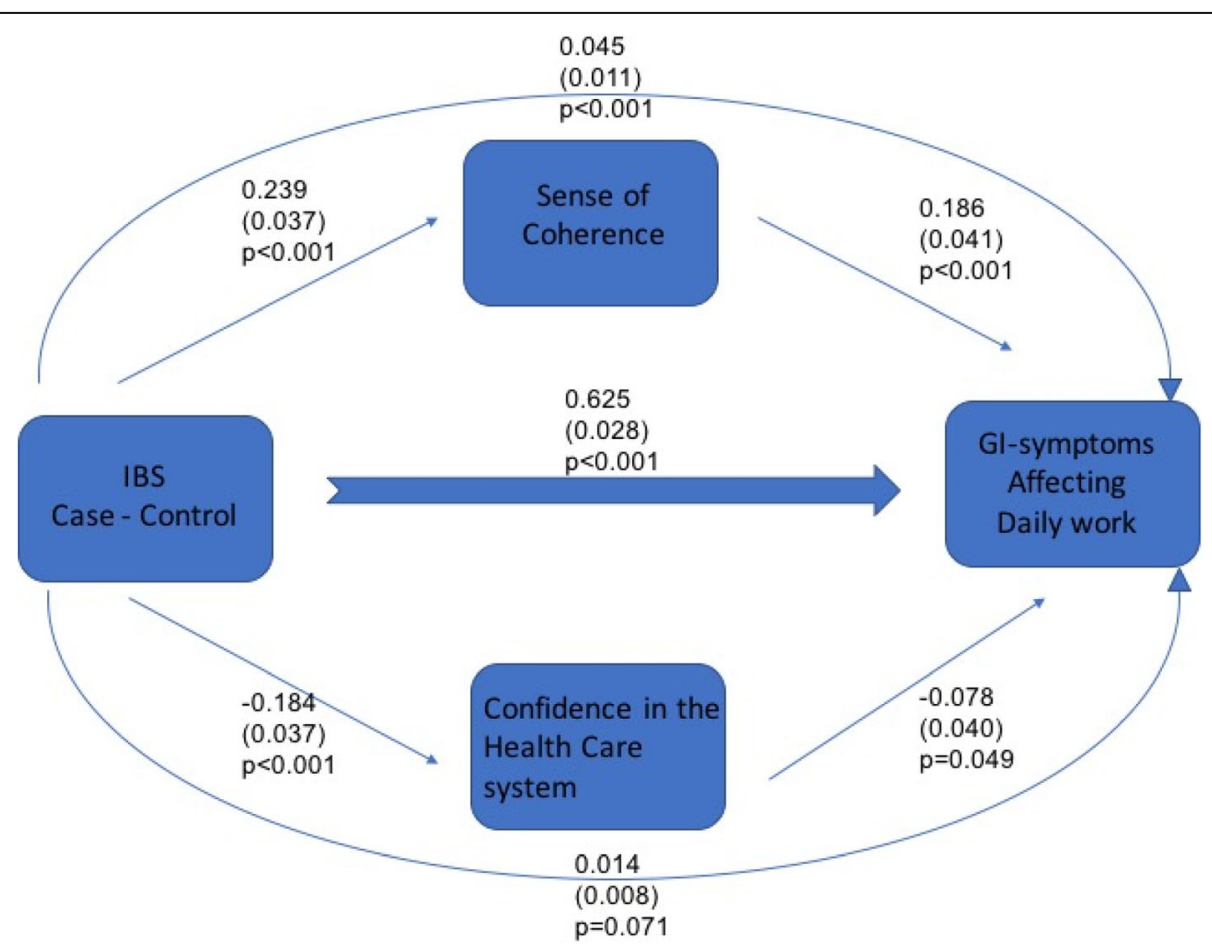

Fig. 1 Analytic framework for the study - A model of potential direct and indirect factors affecting daily performance at work 
than the control group. IBS cases and controls did not differ significantly with respect to sex-ratio, born abroad or occupational status, as shown in Table 1.

Statistically significant differences are reported in Table 2 between IBS cases and controls concerning abdominal pain or discomfort affecting everyday performance at work $(p<0.0001)$ as well as chanced work due to abdominal problems $(p=0.007)$. IBS cases also showed significantly lower $(p=0.001)$ confidence in public health than the control group. Average score on Sense of coherence was also significantly lower $(p<0.0001)$ among IBS cases compared to controls, see Table 2.

Figure 1 implements an a priori identified model of associations between clinically diagnosed IBS status and interference in work by gastrointestinal symptoms. Of primary interest is the direct versus indirect (via Sense of coherence and confidence in the healthcare system) associations between IBS status and interference. The total indirect association between IBS status and interference $(b=0.059, \mathrm{SE}=0.016)$ is small relative to the direct association $(b=0.625, S E=0.028)$, but statistically significant. The indirect association via sense of coherence $(p=0.045)$ is substantially larger and more clearly statistically significant than via confidence in the healthcare system $(p=0.014)$, as shown in Fig. 1. The analytic model shown in Fig. 1 turns out that the correlation between SOC total score and the healthcare seeking is modest and negative $(r=-0.2)$. (This is not shown in the figure).

Table 1 Sociodemographic factors for IBS cases and Controls

\begin{tabular}{|c|c|c|c|c|c|}
\hline \multirow[b]{2}{*}{ Gender } & \multicolumn{2}{|c|}{$\begin{array}{l}\text { IBS cases } \\
(n=299)\end{array}$} & \multicolumn{2}{|c|}{$\begin{array}{l}\text { Controls } \\
(n=369)\end{array}$} & \multirow{2}{*}{$\begin{array}{l}p \text {-value } \\
0.18\end{array}$} \\
\hline & $n$ & $\%$ & $n$ & $\%$ & \\
\hline Male & 65 & 22.0 & 65 & 18.0 & \\
\hline Female & 234 & 78.3 & 304 & 82.4 & \\
\hline Marital status & & & & & $<0.0001$ \\
\hline Living alone & 82 & 28.0 & 62 & 17.0 & \\
\hline Married/cohabitant & 215 & 72.4 & 306 & 83.2 & \\
\hline Education & & & & & 0.002 \\
\hline Low & 51 & 17.1 & 32 & 9.0 & \\
\hline Medium & 136 & 46.0 & 164 & 45.0 & \\
\hline High & 111 & 37.2 & 171 & 47.0 & \\
\hline Occupational status & & & & & 0.31 \\
\hline Employed & 208 & 70.0 & 278 & 75.3 & \\
\hline Student & 23 & 8.0 & 18 & 5.0 & \\
\hline Retired & 40 & 14.0 & 47 & 13.0 & \\
\hline Long - term sick-leave & 13 & 4.4 & 9 & 2.4 & \\
\hline Unemployed & 13 & 4.4 & 17 & 5.0 & \\
\hline Born abroad & 29 & 10.0 & 27 & 7.3 & 0.26 \\
\hline Age mean & 46,7 & & 51,4 & & $<0.0001$ \\
\hline (s.d.) & 13.0 & & 11.8 & & \\
\hline
\end{tabular}

Table 2 Factors related to IBS and work

\begin{tabular}{|c|c|c|c|c|c|}
\hline \multirow[b]{2}{*}{ Factors: } & \multicolumn{2}{|c|}{$\begin{array}{l}\text { IBS cases } \\
(n=299)\end{array}$} & \multicolumn{2}{|c|}{$\begin{array}{l}\text { Controls } \\
(n=369)\end{array}$} & \multirow[t]{2}{*}{$P$-value } \\
\hline & $n$ & $\%$ & $n$ & $\%$ & \\
\hline $\begin{array}{l}\text { Abdominal symptoms affect } \\
\text { performance at work }\end{array}$ & 167 & 78.4 & 51 & 18.0 & $<0.0001$ \\
\hline $\begin{array}{l}\text { Changed work due to abdominal } \\
\text { problem }\end{array}$ & 11 & 5.2 & 2 & 0.9 & 0.007 \\
\hline Confidence in healthcare & & & & & 0.001 \\
\hline Yes & 213 & 72.0 & 307 & 83.4 & \\
\hline Very little or none & 82 & 28.0 & 60 & 16.3 & \\
\hline Do not know & 3 & 1.0 & 1 & 0.3 & \\
\hline Sense of coherence mean & 61.3 & & 67.0 & & $<0.0001$ \\
\hline (s.d.) & 11.6 & & 10.5 & & \\
\hline
\end{tabular}

\section{Discussion}

The negative effects of IBS on everyday working activity have been discussed earlier in the literature [16, 22, 24]. Nevertheless, few studies have focussed on potential direct or indirect factors associated with impaired work productivity among IBS patients. The results of this study add to our understanding of the psychosocial complexity of IBS. The theoretical model that underpins our hypotheses is primarily the biopsychosocial model of George Engel [34], applied to IBS specifically by Doug Drossman $[20,35,36]$. This model allows the social, psychological and behavioural dimensions of illness. Using the concept of the biopsychosocial model might be a good way to explain the interaction between psychological and physiological factors which is often expressed in IBS patients. Our main result in the present study is an association between clinically diagnosed IBS status and interference in work by gastrointestinal symptoms. Of primary interest are the direct versus indirect associations via sense of coherence and confidence in the healthcare system between IBS status and interference in everyday working impairment.

Our primary finding is that both Sense of coherence and confidence in the healthcare system are involved in the association between IBS status and GI symptoms affecting an individual at work. Of further interest is that sense of coherence, which we interpret as a coping strategy, appears to be more important in the association than confidence in the healthcare system. More maladaptive coping strategies have also been shown to be an important factor in previous studies. Our work now suggests it may be part of the mechanism through which IBS has an impact in important aspects of people's lives. Further, improving the coping strategies of IBS patients may therefore improve the quality of life of IBS individuals and help to increase economic productivity.

Our previous research also showed that gastrointestinal symptoms affect daily performance in working life 
in IBS patients and especially female IBS patients reported more frequent short and long-term sick leave due to GI problems than their controls [16] but we were unable to indicate why, until now. Other studies have also reported that IBS patients miss approximately one or two working days per month due to their disease [22, 37]. There may be many explanations for this observed association, including that IBS symptoms may reduce the self-estimated fitness to work through different reasons, including embarrassment when using public toilets, intense abdominal pain, urgency to reach a toilet, fear of faecal soiling [37], faecal incontinence [25] or fatigue [38, 39]. On the other hand, few IBS patients in the present study reported that they had changed their employment due to gastrointestinal problems. Nevertheless, many IBS patients develop personal coping strategies to manage this kind of problem [26, 27]. Both short- and longterm sick leave might be one way to cope with the illness. Our previous study pointed out that long-term sick leave is seen more frequently among IBS patients compared to non-IBS individuals [16]. Our new data suggests that greater use of sick leave may be a reflection of maladaptive coping strategies by IBS patients and this finding is in concordance with consensus from other publications in this field [40-42].

Findings in the present study seem somewhat contradictory, because IBS patients reported lower confidence in the public health system than their controls did, but apparently, they utilise healthcare. Of course, the reported low confidence may be due to extensive use of the healthcare system without cure, which has led to low confidence. Our data are also in concordance with other studies showing that patients with IBS have an increased use of healthcare resources, visit the doctor more frequently, use more diagnostics tests and consume a larger amount of medications than those without IBS [23]. If an individual does not feel the confidence of the community or its representatives, it is unlikely that the individual will seek help when it is needed, potentially leading to more serious health consequences. Unfortunately, we have no data to suggest why IBS healthcare seekers have lower confidence in the public healthcare system than non-IBS healthcare seekers. Another explanation could be that IBS patients simply have more negative experiences with their contact with these institutions. Maybe it reflects inferior coping ability or, as reported in other studies, that IBS patients tend to have more negative early life events such as physical, sexual an emotional abuse [43, 44]. These factors could contribute to less confidence in the community in general, and its support systems in particular.

Our study had both strengths and limitations. One strength is that we used established and validated questionnaires. A possible limitation of using IBS diagnoses made in a PHC (as we have done), is the dependence on the general practitioners' ability to make the correct diagnosis. On the other hand, it could also be a strength, because most IBS patients are diagnosed in primary care. Other strengths are that our selection of a control group, which in this case consists of patients without GI problems, enables us to find associations to IBS itself. Another possible limitation could be the use of self-reported data from questionnaires. A well-known phenomenon to take into consideration when using selfreported data is recall bias, but in general, self-reports are quite reliable and well established [45]. However, what was beyond the scope of the study design was to analyse direct and indirect cost for employers and employees.

\section{Conclusion}

An a priori model shows association between clinically diagnosed IBS status and interference in work by gastrointestinal symptoms. Associations between IBS status and interference were also seen, both direct and indirect via Sense of coherence and confidence in the healthcare system, with sense of coherence appearing to be particularly important. Finally, from IBS patients' and employers' point of view, efforts to treat IBS patients in primary healthcare with cognitive behaviour therapy, by educating patients about IBS, or by learning to cope with the disease might be beneficial for both groups and might also increase the HRQL among this patient group.

\section{Abbreviations}

Fl: Fecal incontinence; Gl: Gastrointestinal; HRQL: Health related quality of life; IBS: Irritable bowel syndrome; IBS-C: Irritable bowel syndrome with constipation; IBS-D: Irritable bowel syndrome with diarrhoea; IBS-M: Irritable bowel syndrome mixed; IBS-U: Irritable bowel syndrome unspecified; PHC: Primary Healthcare Centre; SE: Standard error; SOC: Sense of coherence

\section{Acknowledgements}

We want to thank all the participants and staff at the participating primary care centres, especially Valerie Tegelström and Lisa Wiktorsson, who collected all data.

\section{Authors' contributions}

Concept and design ( $\AA$ F, SW, MJ, TF): acquisition of data ( $\AA$ F, SW, AKN); analysis and interpretation of data ( $\AA \mathrm{F}, \mathrm{MJ}, \mathrm{SW}, \mathrm{TF}, \mathrm{AKN})$; drafting of manuscript ( $\AA F, T F, M J, S W)$ : critical revision of manuscript for important intellectual content ( $\AA F, S W, T F, M J, A K N)$; statistical analysis (MJ, ÅF).

Obtaining funding ( $\AA$ F). All authors read and approved the final manuscript.

\section{Funding}

This study was supported by FORSS - the Research Council of Southeast Sweden.

\section{Availability of data and materials}

The datasets generated and/or analysed during the current study are not publicly available, but are available from the corresponding author on reasonable request.

Ethics approval and consent to participate

All procedures for this study were approved by the Regional Ethical Research Committee at Linköping University (Dnr M41-09). Written informed consent was obtained from all participants. 


\section{Consent for publication}

No individual's personal data is included.

\section{Competing interests}

The authors declare that they have no competing interests.

\section{Author details}

${ }^{1}$ Department of Medicine and Health, Community Medicine, Faculty of Medicine and Health Sciences, Linköping University, SE-581 83 Linköping, Sweden. ${ }^{2}$ Department of Clinical and Experimental Medicine, Division of Gastroenterology, Faculty of Medicine and Health Sciences, Linköping University, Linköping, Sweden. ${ }^{3}$ Psychology Department, Macquarie University, Sydney, NSW, Australia.

Received: 2 August 2017 Accepted: 6 June 2019

Published online: 01 July 2019

\section{References}

1. Longstreath GF. Definition and classification of irritable bowel syndrome. Current consensus and controversies. Gastroenterol Clin N Am. 2005;34(2):173-87.

2. Spiller R, Aziz Q, Creed F, Emmanuel A, Houghton L, Hungin P, Jones R, Kumar D, Rubin G, Trudgill W, Whorwell P. Clinical services committee of the British Society of Gastroenterology. Guidelines on the irritable bowel syndrome: mechanisms and practical management. Gut. 2007;56(12):170-98.

3. Agrèus L, Svärdsudd K, Nyren O, Tibblin G. Irritable bowel syndrome and dyspepsia in the general population: overlap and lack of stability over time. Gastroenterology. 1995;109:671-80.

4. Thompson WG, Heaton KW, Smyth C. Irritable bowel syndrome in general practice: prevalence, characteristics and referral. Gut. 2000;46:78-82.

5. Faresjö ̊, Grodzinsky E, Johansson S, Wallander MA, Foldevi M. Patients with irritable bowel syndrome in Swedish primary care. Eur J Gen Pract. 2006:12:88-90.

6. Guilera M, Balboa A, Mearin F. Bowel habit subtypes and temporal patterns in irritable bowel syndrome: systemic review. Am J Gastroentrol. 2005;100(5):1174-846.

7. Mayer EA, Labus JS, Tillisch K, Cole SW, Baldi P. Towards a system view of IBS. Nat Rev Gastroenterol Hepatol. 2015;12(10):592-605.

8. Mayer EA. Gut feelings: the emerging biology of gut-brain communication. Nat Rev Neurosci. 2011;12(8):453-66.

9. Camilleri M. Peripheral mechanisms in irritable bowel syndrome. The New England J Med. 2012;367(17):1626-35.

10. Camilleri M, Katzka DA. Irritable bowel syndrome: methods, mechanisms, and pathophysiology. Genetic epidemiology and pharmacogenetics in irritable bowel syndrome. Am J Phys. 2012;302(10):G1075-84.

11. Camilleri M, Lasch K, Zhou W. Irritable bowel syndrome: methods, mechanisms, and pathophysiology. The influence of increased permeability, inflammation, and pain in irritable bowel syndrome. Am J Phys. 2012;303(7):G775-85

12. Lee YJ, Park KS. Irritable bowel syndrome: emerging paradigm in pathophysiology. World J Gastroenterol. 2014;20(10):2456-69.

13. Feng B, La JH, Schwartz ES, Gebhart GF. Irritable bowel syndrome: methods, mechanisms, and pathophysiology. Neural and neuro and neuro-immune mechanisms of visceral hypersensitivity in irritable bowel syndrome. Am J Physiol Gastrointest Liver Physiol. 2012;302(10):G1085-98.

14. Herschbach P, Henrich G, Von Rad M. Psychological factors in functional gastrointestinal disorders: characteristics of the disorder or of the illness behaviour? Psychosom Med. 1999;61:148-53.

15. El Serag HB, Olden K, Bjorkman D. Health-related quality of life among persons with irritable bowel syndrome a systematic review. Aliment Pharmacol Ther. 2002;16:1171-85.

16. Faresjö A, Grodzinsky E, Johansson S, Wallander MA, Timpka T, Åkerlind I. A population based case-control study of work and psychosocial problems in patients with irritable bowel syndrome - women are more seriously affected than men. Am J Gastroenterol. 2007;102(2):371-9.

17. Grodzinsky G, Walter S, Viktorsson L, Carlsson AK, Jones MP, Faresjö Å. More negative self-esteem and inferior coping strategies among patients diagnosed with IBS compared with patients without IBS-a case-control study in primary care. BMC Fam Pract. 2015;16:6.
18. Crane C, Martin M. Social learning, affective state and passive coping in irritable bowel syndrome and inflammatory bowel disease. Gen Hosp Psychiatry. 2004;26(1):50-8.

19. Elsenbruch S. Abdominal pain in irritable bowel syndrome: a review of putative psychological neural and neuro-immune mechanisms. Brain, Behaviour and Immunity. 2011;25(3):386-94.

20. Tanaka Y, Kanazawa M, Fukudo S, Drossman DA. Biopsychosocial model of irritable bowel syndrome. J Neurogastroenterol Motil. 2011;17(2):131-9.

21. Talley NJ, Weaver AL, Zinsmeister AR, Melton LJ 3rd. Onset and disappearance of gastrointestinal symptoms and functional gastrointestinal disorders. Am J Epidemiol1992: 136:165-177.

22. Dean BB, Aguilar D, Barghout V, Kahler KH, Frech F, Groves D, Ofman JJ. Impairment in work productivity and health-related quality of life in patients with IBS. Am J Manag Care. 2005;11:S17-26.

23. Spiegel BM. The burden of IBS: looking at metrics. Curr Gastroenterol Rep. 2009;11(4):265-6.

24. Di Bonaventura M, Shawn XS, Bolge SC, Wagner JS, Mody R. Healthrelated quality of life, work productivity and health care resource use associated with constipation predominant irritable bowel syndrome Curr Med Res Opin. 2011;27(11):2213-22. https://doi.org/10.1185/ 03007995.2011 .623157$.

25. Simrèn M, Palsson OS, Heyman S, Bajor A, Törnblom H, Whitehead WE. Fecal incontinence in irritable bowel syndrome: prevalence and associated factors in Swedish and American patients. Neurogastroenterol Moti. 2017;29:e12919. https://doi.org/10.1111/nmo.12919.

26. Voth J, Sirois FM. The role of self-blame and responsibility in adjustment to inflammatory bowel disease. Rehabil Psychol. 2009;54:99-100.

27. Drossman DA, Leserman J, Li Z, Keefe F, Hu YJ, Toomey TC. Effects of coping on health outcome among women with gastrointestinal disorders. Psychosom Med. 2000;62(3):309-17.

28. Grodzinsky E, Hallert C, Faresjö T, Bergfors E, Faresjö A. Could gastrointestinal disorders differ in two close but divergent social environments? Int J Health Geogr. 2012;11(1):5.

29. Statistics-Sweden. Employment, working hours and work environment 1994-95. Sveriges Officiella Statistik. Stockholm: Statistiska Centralbyrån (SCB), 1998 (in Swedish).

30. Whitehead WE. Validation Working Team, Rome Questionnaire Committee. Development and validation of ROME III diagnostic questionnaire. In: Drossman DA, Corazziari, Delvaux M et.al,eds ROME III. The functional Gastrointestinal Disorders, 3rd edn. McLean, 2006.s

31. Antonovsky A. Unraveling the mystery of health: how people manage stress and stay well: san Francicso. USA: Jossey-Bass; 1987.

32. Langius A, Bjorwell $H$, Antonovsky A. The sense of coherence concept and its relation to personality traits in Swedish sample. Scand J Caring Sci. 1992;6:165-7.

33. Nilsson B, Holmgren I, Stegmayr B, Westman G. Sense of coherencestability over time and relation to health, disease and psychosocial changes in a general population: a longitudinal study. Public Health. 2003:1:297-304.

34. Engel $G$. The need for a new medical model: a challenge for biomedicine. Science. 1977:196(4286):129-36.

35. Drossman DA. Gastrointestinal illness and the biopsychosocial model. Psychosom Med. 1998;60(3):258-25867.

36. Frändemark $\AA$, Jakobsson $E$, Törnblom $H$, Simrèn $M$, Jakobsson $S$ Fatigue: a distressing symptom for patients with irritable bowel syndrome. Neurogastroenterol Motil. 2017;29:e12898. https://doi.org/ 10.1111/nmo.12898.

37. Silk DB. Impact of irritable bowel syndrome on personal relationships and working practice. Eur J Gastroenterol Hepatol. 2001;13(11):1327-32.

38. Hahn BA, Kirchdoefer LJ, Fullerton S, Mayer E. Patient-perceived severity of irritable bowel syndrome in relations to symptoms, health, resource utilization and quality of life. Aliment Pharmacol Ther. 1997;11:553-9.

39. Sperber AD, Carmel S, Atzmon Y, Weisberg I, Shalit $Y$, Neumann L, Fich A, Buskila D. The sense of coherence index and the irritable bowel syndrome: a cross-sectional comparison among irritable bowel syndrome patients with and without coexisting fibromyalgia, irritable bowel syndrome non-patients and controls. Scand J Gastroenterol. 1999:34(3):259-63.

40. Motzer SA, Hertig V, Jarett M, Heitkamper MM. Sense of coherence and quality of life in women with and without irritable bowel syndrome. Nurs Res. 2003;52(5):329-37. 
41. Phillips K, Wright BJ, Kent S. Psychosocial predictors of irritable bowel syndrome diagnosis and symptoms severity. J Psychosom Res. 2013;75(5):467-74.

42. Delvaux $M$, Denis $P$, Allemand $H$. Sexual abuse is more frequently reported by IBS patients than patients with organic digestive diseases or controls. Results of a multicenter inquiry. French Club of Digestive Motility Eur J Gastroenterol Hepatol. 1997;9:345-52.

43. Kendall-Tackett KA. Physiological correlates of childhood abuse: chronic in PTSD, depression, and irritable bowel syndrome. Child Abuse Negl. 2000;24:799-810.

44. Baccini F, Pallotta N, Calabreze E, Pezzotti P, Corazziari E. Prevalence of sexual and physical abuse and its relationship with symptom manifestations in patients with chronic organic and functional gastrointestinal disorders. Dig Liver Dis. 2003;35:256-61.

45. Arch GM III, Hueston WJ. Using other people's data: the ins and outs of secondary data analysis. Fam Med. 1997;29(8):568-71.

\section{Publisher's Note}

Springer Nature remains neutral with regard to jurisdictional claims in published maps and institutional affiliations.

Ready to submit your research? Choose BMC and benefit from:

- fast, convenient online submission

- thorough peer review by experienced researchers in your field

- rapid publication on acceptance

- support for research data, including large and complex data types

- gold Open Access which fosters wider collaboration and increased citations

- maximum visibility for your research: over $100 \mathrm{M}$ website views per year

At $\mathrm{BMC}$, research is always in progress.

Learn more biomedcentral.com/submissions 